\title{
Entrevista com o Prof. Dr. Arrigo Leonardo Angelini
}

\begin{abstract}
ARRIGO LEONARDO ANGELINI está entre os mais notáveis psicólogos brasileiros, contribuiu significativamente para a evolução da Psicologia no Brasil tanto como área de conhecimento como profissão. Contribuiu atuando em órgãos de classe e sociedades científicas. Professor dedicado, é responsável pela formação de muitos doutores que atuam no Brasil e mesmo no exterior. Batalhou para que a Psicologia ficasse na Universidade de São Paulo como o Instituto que hoje é, superando a posição de alguns que a queriam como Departamento de outras unidades da Universidade. Sempre atencioso, disponível, um perfeito cavalheiro merece o respeito, o carinho e a atenção de quantos o conheceram mais de perto e puderam partilhar seus esforços no desenvolvimento da Psicologia. Merece um lugar de destaque na história da Psicologia no Brasil.
\end{abstract}

\section{Entrevistadora: Geraldina Porto Witter}

\section{Que variáveis influíram para escolher a Psicologia como área de atuação?}

Quando realizei o curso secundário - naquele tempo, era o ginásio de cinco anos de duração - sempre tive predileção pelas chamadas ciências exatas como matemática, física, química e menor facilidade para as humanidades. Ao término daquele curso, meu interesse, naturalmente, voltou-se para a carreira da engenharia. As escolas da USP, nas diversas carreiras universitárias, mantinham cursos preparatórios denominados "pré" e realizados nas próprias faculdades. Assim, havia o curso pré-médico, o pré-jurídico, o pré-politécnico, entre outros. Era através do "pré" que o estudante ingressava na Universidade. A idade mínima para o ingresso em tais cursos era 16 anos, mas, quando terminei o curso secundário, tinha apenas 15 anos.

Por outro lado, naquele momento, o Colégio Paulistano, instituição onde realizei o curso secundário, estava inaugurando o Curso Normal, destinado à preparação do professor primário, com dois anos de duração e para o qual não havia exigência de idade mínima ao ingressante. Assim, enquanto esperava alcançar a idade para ingressar na Escola Politécnica, resolvi fazer o Curso Normal. Aí, tive o primeiro contato com as disciplinas de natureza pedagógicas e, entre elas, a Psicologia, cujo conteúdo, desde logo, despertou em mim especial interesse. Em 1941, quando terminei o Curso Normal, o Diretor do Colégio Paulistano, Prof. Carlos Pasquale, tendo em vista o excelente desempenho que havia demonstrado naquele curso, aconselhou-me a prosseguir na carreira de educação, pelo ingresso no Curso de Pedagogia da Faculdade de Filosofia, Ciências e Letras da USP. O Curso de Pedagogia era o mais novo daquela Faculdade que fora criada concomitantemente com a fundação da USP em 1934 e concebida como um centro de altos estudos para garantir a integração da Universidade e preparar docentes e pesquisadores nos mais variados campos do saber.

Essa nova Faculdade passou a funcionar mediante a colaboração de numerosos professores estrangeiros contratados para desenvolver novas áreas de pesquisa e docência no ensino superior. Por isso a Faculdade de Filosofia gozava de grande prestígio nos meios universitários e, em suas primeiras turmas, não raro, encontravam-se alunos já diplomados em outros cursos da USP. 
De posse dessas informações e, seguindo o conselho do Prof. Carlos Pasquale, desisti da carreira de engenharia e resolvi ingressar no Curso de Pedagogia da Faculdade de Filosofia, mediante exame vestibular prestado em 1942. Nesse curso, tive a felicidade de ter os mais destacados professores brasileiros na área da Educação, como Fernando de Azevedo (Sociologia Educacional), André Dreyfus (Biologia), Milton da Silva Rodrigues (Estatística), Roldão Lopes de Barros (Filosofia da Educação) e alguns professores estrangeiros como Roger Bastide (Sociologia) e Jean Maugüé (História da Filosofia), entre outros. Mas, acima de tudo, o que me encantava eram as magistrais aulas de Psicologia Educacional da Prof ${ }^{a}$ Noemy da Silve ira Rudolfer que foi, como sabemos, a introdutora de novas técnicas de ensino na Universidade e era a portadora dos conhecimentos dos grandes mestres do "Teachers' College", da Universidade Columbia de New Y ork, onde estivera pouco antes. A Profa. Noemy Rudolfer trouxe para o Brasil as influências de Dewey, Kilpatrick, Gates, Thorndike, Walker, além de outros, e, na época, liderava os esforços de ensino, de investigação e de aplicação da Psicologia em São Paulo.

Quando terminava o Curso de Pedagogia, recebi da Profa. Rudolfer, extremamente honrado, a promessa de que, ao se vagar o cargo de primeiro assistente ocupado pela Prof' Cecília Castro e Silva que, com o casamento, deveria transferir-se definitivamente para os Estados Unidos, eu seria indicado para ocupar aquela função.

\section{Poderia descrever sua formação profissional?}

Em 1944, enquanto aguardava a oportunidade de trabalhar com a Prof' Rudolfer, ainda aluno do $3^{\circ}$ ano do Curso de Pedagogia, fui por ela recomendado ao Engenheiro Ítalo Bologna, Diretor do Centro Ferroviário de Ensino e Seleção Profissional, para exercer em tempo parcial o cargo de assistente técnico naquela instituição. Lá, sob a orientação da Prof' Lourdes de Campos Viegas, iniciei as atividades de pesquisa, elaboração, aplicação e aferição de testes psicológicos destinados à seleção de aprendizes artífices para os cursos profissionais mantidos pelas várias estradas de ferro do Estado de São Paulo, na época, ainda não integradas na FEP ASA. Dentre os inúmeros testes que foram elaborados e estudados naquele centro, cabe destacar a aferição para o Brasil dos testes das Habilidades Primárias de Thurstone, o que foi feito mediante ampla aplicação experimental e sofisticado tratamento estatístico em época na qual ainda não contávamos com as facilidades dos computadores. Com muito entusiasmo, colaborei na pesquisa referente a esses testes e na construção e aferição de numerosas outras provas. O Centro foi extinto e incorporado ao SENAI, vindo a constituir a Divisão de Transportes, passando a exercer as mesmas atividades e onde prossegui com muito empenho e interesse na

mesma função, apenas com uma intenrrupção de dez meses em 1945, durante os quais permaneci no Exército, atendendo convocação para integrar a Força Expedicionária Brasileira. Em virtude do término da Segunda Guerra Mundial, não cheguei a ser enviado ao teatro de operações na Itália, tendo permanecido em quartel sediado no Rio de Janeiro e retomado à vida civil em outubro de 1945.

Em março de 1948, fui nomeado para o cargo de Vice-Diretor do Colégio Estadual e Escola Normal "Cardeal Leme" da cidade de Pinhal no Estado de São Paulo e lá permaneci um ano, até que, finalmente, vagou-se a primeira assistência da Cátedra de Psicologia Educacional. Cumprindo a promessa feita cerca de quatro anos antes, a Profa. Rudolfer indicou-se para exercer o cargo de primeiro assistente, encarregando-me, desde logo, de ministrar as disciplinas Psicologia da 
Aprendizagem e Psicologia da Adolescência para os alunos do Curso de Licenciatura, além de realizar atividades de investigação e de colaborar nos cursos daquela professora.

Tendo sido abertos em 1949 os concursos para ingresso no Magistério Secundário e Normal do Estado de São Paulo, os quais não eram realizados há vários anos, inscrevi-me para a disciplina Educação, com o objetivo de obter um cargo efetivo, pois a função de assistente na USP, naquela época, não oferecia estabilidade e o ocupante poderia ser demitido a qualquer momento. Inscreveram-se, naquele concurso, cerca de 400 candidatos os quais foram submetidos às três provas previstas: escrita, de erudição e didática, além da avaliação dos títulos. Dado o elevado número de candidatos, o concurso prolongou-se durante todo o ano de 1949. Finalmente, apurados os resultados, verificou-se que eu obtivera o primeiro lugar nas notas das provas, porém, quando a estas foi incluída a avaliação dos títulos, na classificação geral, eu obtive o quinto lugar. Como conseqüência desse concurso, fui nomeado em caráter efetivo para o cargo de Professor de Educação do Colégio Estadual e Escola Normal "Dr. Júlio Prestes de Albuquerque", de Sorocaba. Permaneci pouco tempo no exercício, cumulativamente com o de Assistente em tempo parcial, na Faculdade de Filosofia. Isto porque, quando este cargo foi transformado em tempo integral, anualmente a USP encaminhava solicitação ao Secretário da Educação do Estado de São Paulo para que eu fosse colocado à disposição da Faculdade de Filosofia a fim de continuar como primeiro assistente da Cátedra de Psicologia Educacional.

Nos anos de 1950 e 1951, realizei o Curso de Especialização em Psicologia Educacional, nos termos da Portaria Ministerial N.o 328 de 13/05/47 que previa ao diploma a outorga do título de Especialista.

Nas férias de verão de 1950, usufruindo de viagem de estudos, permaneci um mês na Universidade do Chile, em Santiago, onde realizei cursos intensivos de diversas disciplinas de natureza psicológica com destacados professores que compunham o corpo docente da Escola de Psicologia, pois, já naquela época, aquela universidade dispunha de tal unidade de ensino, o que entre nós veio a ocorrer somente muito mais tarde.

Em 1952, realizei viagem aos Estados Unidos com o objetivo de visitar Departamentos de Psicologia de diversas universidades como as de Stanford, Berkeley, Chicago, Northwestern e Columbia. Na Universidade Northwestern, em Illinois, procurei o Prof. Benton J. Underwood que vinha pesquisando na área de psicologia da aprendizagem, pois eu ministrava essa disciplina aqui e já havia feito algumas pesquisas nessa área. Com algumas sugestões do Prof. Underwood, planejei um experimento sobre aprendizagem serial verbal, o qual resultou em minha tese de doutorado, aprovada com distinção em 1953. O tema propriamente dito versou sobre a influência dos fatores similaridade intra-serial e derivação inter-serial na aprendizagem verbal, sendo que os resultados experimentais obtidos ensejaram a formulação de uma nova hipótese explicativa da curva de posição serial, inédita, portanto, na literatura da matéria.

Quando visitei a Universidade de Chicago, entrevistei-me demoradamente com o Prof. Louis Leon Thurstone que, naquela época, estava em grande proeminência em virtude de suas contribuições para a Psicometria e, especialmente, para a teoria da inteligência. Transmiti a ele os resultados da aferição do seu Teste de Habilidades Primárias, realizada aqui no Centro Ferroviário de Ensino e Seleção Profissional. Além disso, tomei conhecimento dos vários instrumentos de sua autoria para avaliação de atitudes, temperamento e interesses. Chamou-me particularmente a atenção o "Interest Schedule", um inventário de interesse que julguei ótimo para o nosso meio, tão 
carente de instrumentos psicológicos. Traduzi, adaptei e aferi esse instrumento, mediante aplicação experimental em adolescentes de ambos os sexos, estudantes de segundo grau. Essa pesquisa constituiu parte de minha tese de Livre-Docência intitulada $\mathbf{O}$ papel dos interesses na escolha da profissão, defendida em concurso realizado em 1954 na Cátedra de Psicologia Educacional da USP. Posteriormente, esse trabalho foi publicado no México pela Editora Trillas sob o título Inventário de Interesses;

Ainda em 1954, realizei outra viagem aos Estados Unidos e ao Canadá. Neste país, visitei o Departamento de Psicologia da Universidade Mc Gill e da Universidade de Montreal e, nos Estados Unidos, realizei um estágio de cerca de um mês no Departamento de Psicologia da Universidade de Michigan, em Ann Arbor. Lá entrei em contato com o Prof. John W. Atkinson que vinha trabalhando em uma nova técnica projetiva destinada a avaliar a motivação humana, por ele desenvolvida em colaboração com Russell A. Clark, da mesma universidade, Edgar L. Lowell, da Universidade de Harvard e sob a direção de David C.McClelland da Universidade Wesleyan. Durante esse estágio na Universidade de Michigan, discuti amplamente com o Prof. Atkinson um plano de pesquisa sobre aquela nova técnica, com o objetivo de aferi-la para o nosso meio. Assim, elaborei e executei um amplo projeto de investigação, trabalho que me levou a redigir tese que foi submetida em 1956 ao concurso para o provimento do cargo de Professor Catedrático de Psicologia Educacional da USP em caráter efetivo, uma vez que, desde 1954, com a aposentadoria da Profa. Noemy Rudolfer, já vinha exercendo esse cargo interinamente. Posteriormente essa tese foi publicada pela Livraria José Olympio Editora sob o título Motivação Humana.

Minha formação profissional foi complementada pela participação, no período de 1950 a 1997, em 65 congressos ou outras reuniões

científicas realizadas no Brasil ou no exterior, sempre com a apresentação de trabalhos, geralmente resultados de pesquisas.

\section{Por que optou por Psicologia Educacional/Escolar?}

De um lado, minha formação de professor primário, professor secundário de Educação e professor universitário provindo do Curso de Pedagogia e, por outro lado, o fato de que a Psicologia em nosso meio floresceu a partir das primeiras décadas deste século, principalmente graças às pesquisas e às aplicações pioneiras dos educadores, levaram-me, necessariamente, para a área educacional. Quando iniciei minhas atividades docentes e de pesquisa, as maiores demandas de estudos de natureza psicológica eram exatamente na área da Educação. Não havia cursos de Psicologia para a formação do psicólogo. O que havia eram disciplinas de natureza psicológica em cursos de nível secundário como o Normal e em alguns cursos universitários, especialmente no de Pedagogia. Minha vocação era, sobretudo, para a pesquisa experimental de base estatística, o que talvez se explique pela maior facilidade para as ciências exatas manifestadas no curso secundário, como mencionei inicialmente. A Psicologia Experimental, como é geralmente entendida atualmente, era praticamente inexistente, a Psicologia Social extremamente incipiente e a Psicologia Clínica exerci da modestamente em algumas instituições de saúde, como o Serviço de Higiene Mental do Estado. É verdade que a Psicologia Aplicada ao Trabalho já existia em algumas instituições como o SENAI, o SENAC e o IDORT, mas cabe ressaltar que, em todas essas áreas além da Educação propriamente dita, os trabalhadores da psicologia eram geralmente professores primários formados pelas antigas Escolas Normais, autodidatas ou estrangeiros aqui radicados. 


\section{O senhor foi Catedrático de Psicologia Educacional e, posteriormente, Diretor e Chefe do PSA do Instituto de Psicologia da USP, dedicando grande parte de seu tempo ao desenvolvimento da área como pesquisador, administrador e formador de Recursos Humanos. Poderia contar um pouco desta vivência uspiana?}

Durante 40 anos de exercício na USP, com exceção de dois apenas, um dos quais em que permaneci como Professor Visitante da Escola de Psicologia da Universidade da Venezuela, onde inaugurei os cursos de pós-graduação e outro como Professor Visitante do Departamento de Psicologia Educacional da Universidade do Texas, nos Estados Unidos, dediquei-me integralmente ao ensino, à pesquisa, à administração e à formação de recursos humanos. Até 1969, fui o responsável pela Cátedra de Psicologia Educacional da Faculdade de Filosofia, Ciências e Letras da USP. No Instituto de Psicologia, criado por minha insistente proposta junto ao Conselho Universitário, colegiado do qual eu não fazia parte, exerci, a partir da Reforma Universitária de 1970, três mandatos de Diretor e dois de Vice-Diretor e, neste caso, concomitantemente com a Chefia do Departamento de Psicologia da Aprendizagem do Desenvolvimento e da Personalidade. Como Diretor, procurei desenvolver o ensino, a pesquisa e a prestação de serviços à comunidade nos quatro Departamentos criados no Instituto e dediquei especial atenção à formação da biblioteca, hoje considerada uma das melhores do país, no caso da Psicologia. Instalei a pós-graduação nas áreas Escolar, Experimental, Social e Clínica, nos níveis de mestrado e doutorado; propugnei pela ampliação das instalações do Instituto que, de início, eram muito restritas e extremamente precárias e estimulei a realização de concursos por parte dos docentes para que pudessem ascender a níveis mais elevados da carreira. Neste particular, cabe lembrar que, durante as minhas gestões como Diretor, foram realizados seis concursos para Professor Titular, vários para Livre-Docente e um número muito maior ainda para os títulos de Doutor e de Mestre. Embora as atividades administrativas absorvessem a quase totalidade do meu tempo, jamais deixei de participar do ensino, o que fazia no Curso de Pós-Graduação em Psicologia Escolar, inclusive orientando vários mestrandos e doutorandos, além de realizar as minha próprias pesquisas. No Departamento, procurei sempre estimular a realização de pesquisas na área Educacional, cabendo destacar o amplo projeto internacional, realizado em oito países, cujo início se deu ainda na Cátedra de Psicologia Educacional da Faculdade de Filosofia, sob o título "Coping Styles and Achivement, A crossnational study of school children", coordenado pelo Prof. Robert F. Peck, da Universidade do Texas e subvencionado pelo "Office of Education and Welfare", dos Estados Unidos. No Brasil, o projeto foi desenvolvido sob minha direção e dela participaram vários docentes do PSA, sendo que parte dos dados obtidos ensejaram a realização de vários trabalhos apresentados em congressos e três teses de doutoramento. Os resultados gerais dessa pesquisa foram publicados pelo "Office of Education" acima mencionado.

\section{O senhor foi um dos que batalharam para que a Psicologia no Brasil fosse instituída como profissão e foi o primeiro presidente do CFP. Neste contexto, como ficou a Psicologia Escolar/Educadonal no seu trabalho?}

Por volta de 1958, começava a se tomar mais evidente a necessidade de se regulamentar a profissão de psicólogo no Brasil e de se estabelecerem os requisitos mínimos para a formação desse profissional. Na época, as aplicações da Psicologia e alguns esforços de investigação nesta área eram realizados principalmente em instituições educacionais, em serviços de seleção e orientação 
profissional ou em instituições de saúde, inicialmente, por pessoas formadas pelas antigas escolas normais, as quais completavam sua formação no próprio trabalho e, posteriormente, pelos primeiros formados nos cursos de Pedagogia ou de Filosofia e por alguns egressos da Escola de Sociologia e Política, entidade complementar da USP, além, naturalmente, de alguns psicólogos estrangeiros aqui radicados. Não havia, portanto, a figura do psicólogo como profissional liberal e nem existia a formação específica desse profissional. Daí a campanha da qual participei junto ao Congresso Nacional no sentido de se aprovar Lei que regulamentasse a profissão e estabelecesse a respectiva formação. Dessa companha participaram também os professores da Cátedra de Psicologia da Faculdade de Filosofia, a Sociedade de Psicologia de São Paulo e a Associação Brasileira de Psicologia, além dos aportes provindos de outros Estados da Federação. Acredito que, no texto da Lei, finalmente sancionada em 27 de agosto de 1962, as atividades relativas à aplicação da Psicologia à Educação ficaram bem caracterizadas como uma das funções privativas do psicólogo. A grande dificuldade para a tramitação do projeto no Congresso Nacional provinha da resistência da área médica que não admitia o psicólogo como profissional independente na realização das funções relativas à clínica e à psicoterapia. Por isso, estas expressões não constam do texto legal e tiveram que ser substituídas por "solução de problemas de ajustamento", para melhor aceitação por parte dos médicos.

A Lei N.O 4119/62 que regulamentou a profissão no País e dispôs sobre a formação do psicólogo foi complementada pelo Parecer N. ${ }^{\circ}$ 403/62 do Conselho Federal de Educação que estabeleceu o currículo mínimo para os respectivos cursos. Entretanto a Lei não criou os órgãos de classe que deveriam fiscalizar o exercício profissional. Isto só ocorreu nove anos mais tarde por outra Lei, a de N. ${ }^{\circ} 5766 / 71$, que criou o Conselho Federal e os Conselho Regionais, como resultante de insistentes solicitações das associações de psicologia existentes na época. Mais dois anos se passaram após a aprovação desta Segunda Lei para que o Ministério do Trabalho, que era o órgão competente, resolvesse convocar as associações de psicologia com a finalidade de organizar o primeiro Conselho Federal. Isto ocorreu em 20 de dezembro de 1973, ocasião em que eu fui aclamado o primeiro Presidente daquela autarquia e, no ano seguinte, já instalava os oito primeiros Conselhos Regionais de Psicologia no País.

\section{Como vê hoje a Psicologia Escolar/Educacional no Brasil?}

Historicamente, a Educação foi a principal vertente para o desenvolvimento da Psicologia em nosso meio. Atualmente, a Psicologia Escolar/Educacional é um dos mais importantes campos de atuação do psicólogo, tanto em termos de ensino e pesquisa como nas aplicações práticas. Uma comprovação dessa assertiva é encontrada no expressivo número de estudiosos e pesquisadores nessa área e na conseqüente produção científica em termos de teses de doutorado, dissertações de meStrado e outras publicações de alto nível magnificamente representadas pelo conteúdo da revista de Psicologia Escolar e Educacional da ABRAPEE. Sem desprezar outros campos de atuação do psicólogo, acredito que o escolar/educacional seja o que melhor responde às necessidades do nosso País, na consideração dos problemas de educação. O conhecimento psicológico no campo experimental, por exemplo, e mesmo em grande parte do clínico, poderá ser melhor aferido em países mais desenvolvidos, que possuam maiores recursos humanos e principalmente recursos materiais. Dificilmente poderemos competir nessas áreas com os laboratórios sofisticados, o grande número de cientistas e os amplos recursos orçamentários disponíveis naqueles países. Entretanto as 
facilidades existentes lá fora, obviamente, não podem ser utilizadas para resolver as questões educacionais e escolares brasileiras. Estes problemas devem ser resolvidos aqui, com os nossos recursos e daí a importância desta área no Brasil.

\section{Qual o futuro da Psicologia Escolar/Educacional no Brasil?}

Acredito que esteja reservado à Psicologia Educacional em geral e à Escolar em particular um futuro da maior significação não apenas no Brasil, mas no mundo todo. Devido às mudanças tecnológicas extremamente rápidas que impõem ao homem novos estilos de vida e sobretudo novas exigências de preparação para o convívio em sociedade e para o exercício profissional, os problemas educacionais representam um desafio crescente para os pesquisadores, especialistas na área da psicologia.

\section{Se pudesse refazer sua trajetória profissional na psicologia, escolheria outra área? Por quê?}

Como tentei relatar acima, minha formação acadêmica e as oportunidades de trabalho de que pude usufruir levaram-me naturalmente para a área da Psicologia Educacional. Nesta área, sempre tive predileção pela pesquisa. Lamento apenas que as atividades administrativas que desempenhei não me permitiram realizar mais em termos de pesquisa. De fato, se recordar que, durante minha trajetória profissional, fui Chefe de Cátedra, Coordenador do Curso de Psicologia da Faculdade de Filosofia, Diretor do Instituto de Psicologia durante três mandatos e Vice-Diretor durante dois outros, Chefe de Departamento, Presidente da Sociedade de Psicologia em duas gestões, Presidente da Associação Brasileira de Psicologia, Presidente do Conselho Federal de Psicologia e Presidente da "Interamerican Society of Psychology", além de outras atividades associativas de menor expressão, fica claro que essas funções administrativas absorveram grande parte do tempo que seria disponível para a investigação psicológica. Assim, se pudesse refazer minha trajetória profissional, gostaria de trabalhar na mesma área, porém com a esperança de poder-me dedicar mais à atividade de pesquisa.

Agradeço a honra que me é conferida com a solicitação da presente entrevista e espero que o resgate de algumas informações sobre a minha carreira profissional, a qual coincidiu com as grandes transformações da Psicologia em nosso meio, possa servir como estímulo para os que desejam estudar a história da ciência psicológica em nosso País.

Agradeço, particularmente, à minha entrevistadora, Profa. Dra. Geraldina Porto Witter, excolaboradora na Faculdade de Filosofia e no Instituto de Psicologia da USP e, atualmente, um dos baluartes da Psicologia Escolar e Educacional no Brasil. 